\title{
Effect of Minimum Quantity Lubrication System for Improving Surface Roughness in Turning Operation
}

\author{
Shazzad Hossain and Mohammad Zoynal Abedin
}

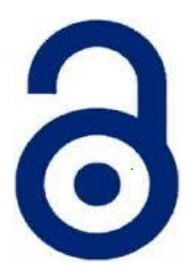

\author{
Received: 21 October 2020 \\ Accepted: 29 December 2020 \\ Published: 30 January 2021 \\ Publisher: Deer Hill Publications \\ (c) 2021 The Author(s) \\ Creative Commons: CC BY 4.0
}

\begin{abstract}
Due to increase in temperature at the cutting zone, the tool wear and surface roughness along with the non-uniform chip formation and the dimensional deviation of the job by using the conventional cutting fluid, the machining operation experts have directed their concentrations in order to achieve a smooth machining operation by using minimum quantity lubrication (MQL). As a consequence, numerous efforts can be seen for not only having the optimum cutting parameters but also other parameters that enhance the product quality and the surface roughness. In this regard, relevant experimental and numerical data outcomes not only MQL but also conventional cutting fluid (CCF) in the turning operation of 50HRC steel has been investigated experimentally. It is revealed that the surface roughness becomes optimal and significantly reduced for the condition of MQL with that of dry and conventional flood.
\end{abstract}

Keywords: Turning operation, CCF, MQL, Surface roughness, Lathe machine.

\section{INTRODUCTION}

Minimum quantity lubrication or MQL, also known as "Micro lubrication", is the new method of delivering metal cutting fluid to the chip-tool interface. Using this method, a little fluid, when properly selected and applied, can make a substantial difference in how effectively a tool performs in the operation. The goal of any machining operation such as turning, milling, grinding, drilling, etc. is to reduce the machining costs by improving its quality and productivity. The machining operation is performed by using an extensive lubrication that helps not only to reduce the friction, heat and wear of cutting tools but also helps to ensure a smooth operation between the cutting tools and work pieces. In ancient time, the conventional cutting fluid (CCF) was seen to be highly used in various machining processes that would cause the tremendous health problems of employees as well as environmental pollutions. In addition, by using CCF, it may not be possible to achieve more working satisfactions due to its various reasons such as the recycling of its chips, degrading the quality of fluid and less heat absorbing capacity of the fluid and so on. Also, the CCF is considered to be more effective at a lower cutting speed and it becomes ineffective at a higher cutting speed because the amount of generated heat is more and the coolant cannot reach the critical areas, hence the interface cannot be cooled easily. Thus, the minimum quantity lubrication system comes out as another method that can be studied in details so as to reach the desired objectives and that may be considered to be an economical and environmentally compatible lubrication system in the machining operation.

The MQL system provides spray painting at high speed and high pressure to the cutting zone by the gun. It is supplied at a constant pressure around 2 to 6 bars. Basically, a mixture of air and cutting fluid (soluble oils, semi synthetics, and synthetics) is applied onto the cutting zone. Different papers published on MQL in different types of machining process. MQL is an advanced method which can perform the superior cutting operation where the temperature at the cutting zone promotes a favorable chip formation and tool wear that leads to have an enhanced tool life and surface finish. The quality of surface is most significant foe any product. The surface roughness is main affecting thing such as for contact causing surface friction, wearing, in production time it is generating high cutting zone temperature. Such high temperature list to have a dimensional deviation and enhance premature failure of cutting tools. In high cutting speed machining, it is clear that conventional cutting fluid application fails to penetrate the chip-tool interface and thus cannot remove heat effectively. Lubrication and heat removal are the basic ways to keep the tool wear under control. But the conventional cutting fluid effective at lower cutting speed and gets ineffective at higher cutting

Shazzad Hossain and Mohammad Zoynal Abedin $₫$

Department of Mechanical Engineering

Dhaka University of Engineering and Technology

Gazipur 1707, Bangladesh

E-mail: abedin.mzoynal@duet.ac.bd

Reference: Hossain S and Abedin, M. Z. (2021). Effect of Minimum Quantity Lubrication System for Improving Surface Roughness in Turning Operation. International Journal of Engineering Materials and Manufacture, 6(1), 50-59. 
speeds and feed, because the amount of heat generation in cutting zone is high. It is also shown rough results in high depth of cut in machining. The coolant cannot reach the critical areas and the tool work piece area or cutting zone area cannot be cooled. Solving this problem, it is widely used in various machining operation minimum quantity lubrication (MQL) method due to its huge advantages. This is possible if machining is carried out at maximum cutting parameters and at the same time able to achieve enhanced tool life (TL). When the high pressure soluble oil is used on the chip tool interface, it can reduce the cutting temperature and improve the tool life and surface finish to a certain extent. The prospect of using overflow coolant in high speed machining (HSM) is not very optimistic. Most coolants, especially water-based coolants, have a negative impact on tool life. MQL is one of the new system in which a very small amount of oil is pulverized into a compressed air steam. MQL helps to reduce the cutting temperature and avoids the thermal shock of flooded coolant. Given the high costs associated with the use of cutting fluids, and when it comes to enforcing stricter environmental regulations, the choice of MQL seems obvious. Furthermore, MQL also reduces the cutting force, power consumption, tool wear, nodal temperature and friction coefficient. Authors have also identified the research gaps for further research.

Although there have been many review articles on this topic. Here in this study tries to find out major advantages using MQL on machining process from various established journal. So that in future it will help going on further research on MQL. The present work reviewed some papers on MQL and experimentally investigates the role of $\mathrm{MQL}$ on surface roughness in turning operation of CNC lathe machine. The wealth of nations can be judged by their investment in machining. Modern manufacturing trends require parts to be produced quickly and smoothly. Although there have been many review articles on this topic, this attempt has its own merits. It highlights the operational parameters that have been left untouched and can be proved very useful for any future studies in this field.as a significant enhancer. For convenient usage, passive techniques are important topics for scientists and researchers during recent decades. Innumerable experimental studies have been conducted to improve the heat transfer rates by these techniques. Scientists preferred passive heat transfer enhancement techniques due to their simplicity and applicability in many applications [1]. In recent years, heat transfer technology has been widely applied to refrigeration and air conditioning, automobile, process industries, etc. The main purpose of heat transfer enhancement techniques is to reduce the thermal resistance either by achieving the effective heat transfer surface area or by creating turbulence in the fluid flowing inside the tube. There are various arrangements are used and experimented to get better heat transfer rate such as insertion in tubes, the tube with fins, different tube shapes, corrugated tubes, baffle arrangements as well as different mediums like water, air, and nanofluids. The rearrangements of these different components are used for obtaining various purposes like increases the surface contact area of the fluid, create a swirl in the flow, and decrease the pressure drop to get enhancement heat transfer rates [2].

Overall, rough surfaces or extended surfaces are used to increasing the effective surface area whereas inserts, winglets, turbulators, etc. are used for generating the turbulence [3]. Based on scientific experiences, various types of inserts such as modified twisted tapes, wire coil, baffles, wire mesh, longitudinal swirl generators, and other types of tube inserts have been designed and studied numerically or experimentally. Some researchers summarized the functions of different types of the insert which mainly enhanced single-phase convective heat transfer in heat exchangers by mixing main flow and the turbulence in the boundary layer region [4].

In recent years, heat transfer technology has been widely applied to devise applications in refrigeration, automotive, method industries as heat exchanger system. Heat exchanger systems are used in different processes like conversion, utilization and recovery of thermal energy in various industrial, domestic applications and commercial processes. The most common examples include steam generation and condensation in power cogeneration plants widely used the heat exchanger to get better performance. The heating and cooling in thermal processing of pharmaceutical products manufacturing, chemicals industries and waste heat recovery plants are also utilizing the heat enhancement process by various enhancer to increase the heat exchanger efficiency. The increase in heat transfer performance can lead to a more economical design of heat exchanger which can help to make savings of energy, materials and cost which is related to a heat exchange process. This design also obeys many techniques termed as heat transfer augmentation which has an indicative impact on the enhancement of thermal performance. The present study investigated the heat transfer enhancement in various arrangements with insert devices as an important passive technique and their impacts on different mediums and configurations.

\section{RECENT LITERATURE SURVEY ON MQL}

In the pursuit toward achieving dry cutting, air machining, minimum quantity lubrication system in machining are the stepping stones. Nevertheless, machining is always accompanied by certain difficulties, and hence none of these methods has provided a complete solution. Dhar et al. [1] investigated the role of minimum quantity lubrication on cutting temperature, tool wear, surface roughness, and dimensional deviation in turning of AISI-4340 steel at cutting speed and feed rate combinations by uncoated carbide insert and found a significant result on tool wear rate, dimensional inaccuracy and surface roughness by using MQ. MQL helps to reduce the cutting temperature and avoids the thermal shock [2]. Lugscheider et al. [3] used this technique in remaining process of gray cast iron and aluminum alloy with coated carbide tools and concluded that it caused a reduction of tool wear when compared with the completely dry process and as a result an improvement in the surface quality of the holes. Dhar et al. [4] also used this method in turning process of medium carbine steel and found that, in some cases, a mixture of air and soluble 
oil has been shown to be better than overhead flooding application of soluble oil. The drilling of aluminum silicon alloys is one of those processes where dry cutting is impossible due to the high ductility of the work piece material [5]. Without cooling and lubrication, the chip sticks to the tool and breaks it in a very short cutting time. Therefore, in this process a good alternative is the use of the MQL method $[6,7]$. Khan et al. [8] described that, MQL provides environment friendliness with machining (maintaining neat, clean and dry working area, avoiding inconvenience and health hazards due to heat, smoke, fumes, gases, etc. and preventing pollution of the surroundings) and improves the machinability characteristics.

Dhar et al. [9] compared the mechanical performance of MQL to completely dry lubrication for the turning of AISI1040 steel based on experimental measurement of cutting temperature, chip reduction coefficient, cutting forces, tool wears, surface finish, and dimensional deviation. Results found that the use of near dry lubrication leads to lower cutting temperature and cutting force, favorable chip-tool interaction, reduced tool wears, surface roughness, and dimensional deviation. The increasing demand for high machine productivity requires the use of high cutting speeds and feed speeds. This processing inherently produces high cutting temperatures, which not only shortens tool life, but also impairs product quality. Metal cutting fluids have changed the performance of machining operations due to their lubrication, cooling and chip removal functions, but in terms of employee health and environmental pollution, the use of cutting fluids has become a problem $[10,11]$. They suggested MQL mainly by which reduction the cutting zone temperature and favorable change in the chip-tool and work-tool interaction. Productivity of any machine tool and any tool Processing parts depends on the quality of the parts the surface produced by the machine. So for the good functional behavior of any mechanical parts good surface quality is essential [12].

Lohar and Nanavaty [13] describes that the surface in hard turning of hardened AISI 4340 is better as compare to dry and wet turning. There is $30 \%$ improvement in surface finish using MQL of turning operation and use the Analysis of variance (ANOVA) is carried out using MINITAB software to investigate difference in average performance of factors using test. As usual hard turning process requires large quantities of coolants and lubricants for machining. The cost of associated with lubricants increases the total cost of production and conventional cutting fluid application fails to penetrate the chip-tool interface. Thus conventional cutting fluid cannot remove heat effectively. Considering cost and the environmental laws are enforced, alternatives has been sought to minimize the use of cutting fluid in machining operations. Some of these are dry machining and machining with Minimum Quantity Lubrication (MQL). Kedare et al. [14] found that the surface finish improved by $27 \%$ using MQL system during end milling operation. The results of this study show that MQL can be considered an economical and environmentally friendly lubrication technology.

Y S Laio et al. [15] described that the tool life significantly improved by MQL in HSM of NAK80 hardened steels when cutting parameters are selected properly. MQL is the name given to the process in which very small amount of oil is pulverized into the flow of compressed air. MQL helps in reducing cutting temperature and also averts thermal shocks, experienced by flood coolant. Zhou et al. [16] has investigated of surface damage produced by whisker-reinforced ceramic cutting tools in the finish turning of Inconel 718 (nickel-based super alloy). The aim of this study is the effects of the cutting parameters (cutting speed, depth of cut and feed), tool wear and Coolant conditions on the surface damage to it occurring during dry and wet turning. MQL shows better result at slow cutting speed and low depth of cut. As per as MQL is concerned surface roughness value is almost constant with little variations. Surface finish of MQL is better with medium cutting speed. The main objective of this paper is MQL provides the benefits mainly by reducing the cutting temperature, which improves cooling effect and results in better surface finish. Cakir et al. [17] has investigated the AISI 1040 steel by turning process, the effects of cutting fluid, application of some gases and dry cutting on cutting force, thrust force, surface roughness, friction coefficient and shear angle were studied. Dry machining, wet machining and machining with oxygen, nitrogen and carbon dioxide gases were carried out under constant cutting speed, three level of feed and depth of cut. Chrong-Jyh et al. [18] has investigated the optimization of CNC turning operation parameters like speed, feed and depth of cut for SKD11 (JIS) using the Taguchi and Grey relational analysis method. The cutting tool is made of carbide and coated with titanium nitride (TiN) and Watersoluble cutting fluids are mixed with water at different ratios depending on the machining operation.

Rajan and Philip by using AISI 4340 steel and the combination has been studied and compared with dry and wet turning under the parameters of speed nation of SNMC 120408 and P30 tool material, hard turning with minimal cutting fluid (HTMF, feed, depth of cut [19]. So the surface roughness is used as an indicator of the quality of any product. It Influences such as wear resistance, fatigue strength, Coefficient of friction, corrosion resistance, and lubricity, wear the speed of processing the part. In today's manufacturing Industry quality is one of the important factors, the only Components that affect customer satisfaction. In every industrial field, the surface quality is determined by the surface roughness of the component [20,21].

Tsai et al. [22] found that the cooling ability of water in terms of temperature drop decreases with an increase in both temperature and depth of cuts. So, this might be the reason for flood cooling having no effect at higher depth of cuts, while the effect for MQL might be due to inadequate lubrication. Lajis et al. [23] described that the machining temperature at the cutting zone is an important index of machinability and needs to be controlled as far as possible. MQL is expected to provide some favourable effects mainly through reduction in cutting temperature. When the chip-tool contact is partially elastic, where the chip leaves the tool, MQL is dragged in that elastic contact zone in small quantity by capillary effect and is likely to enable more effective cooling [23]. Brain Boswell, Mohammad Nazrul Islam, state that, the experimentation involved in determining a suitable environment alternative to using 
little amount of cutting fluid in high speed velocity at cutting zone. As a result they observed and found that reduce thermal shock and stresses generating during machining [24].

The MQL systems enabled reduction in average chip tool interface temperature up to $10 \%$ as compared to using conventional cutting fluid. Most of the authors have indicated adequate betterment in performance with MQL machining compared to dry machining, and more meaningful results could have been obtained if it was also compared with flood machining. Surface quality of the machined parts is one of the most important product quality indicators and most frequent customer requirements which can be obtained by MQL processing and get accurate finishing than conventional fluid.

Cha et al. [25] found that Inconel 718 alloy is widely used as material of aircraft engine, has a good mechanical property in high temperature, strong anti-oxidation characteristics in oxidized current over $900 \circ \mathrm{C} 900 \circ \mathrm{C}$, and also is not easily digested in the air containing sulfur, therefore, its usage as mechanical component is expanding rapidly. Even though Inconel alloy 718 is difficult to machine, it requires highly precise processing/machining to sustain its component quality of high accuracy. In this paper, general turning operation conditions arc tested to select the best cutting process condition by measuring surface roughness through implementing experiments with orthogonal array of cutting speed, feeding speed and cutting depth as processing parameters based on the Taguchi method. Optimal turning operation conditions are extracted from the proposed experimental models.

Lee et al. [26] suggested in their research how to derive optimum cutting conditions for the milling process in MQL machining. To reach these goals, a bunch of finish milling experiments was carried out while varying cutting speed, feed rate, oil quantity, depth of cut and so on with MQL. Patil et al. [27] characterized airborne micro droplet diameters and size distribution from two commercially available lubricants $A$ and $B$ for internal minimum quantity lubrication (MQL).

\section{MQL SYSTEM SET UP AND ITS APPLICATIONS}

In general, there are two methods are widely used in machining process one is external spray and another is throughtool. The external spray system made by a coolant tank or reservoir which is connected with tubes fitted with one or more nozzles. It is easy method than others, inexpensive, portable, and suited for almost all machining operations. Through-tool MQL systems are available in two configurations: based on the method of creating the air-oil mist. The first is the external mixing others name is one channel system. Here, the oil and air are mixed externally, and piped through the spindle and tool to the cutting zone. Minimum quantity lubrication and dry metalworking system is the most recent and quickly modern technology. This technology was mainly developed in the aerospace industry because the scale of the work amplified the negative attributes of the conventional flood type coolant and it was not possible surface quality requirements by using dry machining. This type of lubrication system can apply anywhere would like to maximize tool life without the conventional coolant mess. Such as- Aluminum, steels, HSLA, super alloys, tool steel, copper and brass. Various process like as-Lathe operation, grinding, CNC profiling, turning, and drilling, milling, etc. To extend the life time of cutting tools and reduces friction between work piece and cutting edges MQL contributes a lot. Its assists in smoothing and quick operation. Obviously the health and safety aspects of using cutting fluids add to the cost of metal cutting as suitable disposal of the cutting fluid is needed. Most of the researcher have showed a noticeable improvement in performance with MQL machining and more meaningful results could have been obtained. MQL very useful on hard machining process because of its high pressure jet flow, good mixture of coolant and applied at the chip-tool interfaces and could reduce cutting temperature.

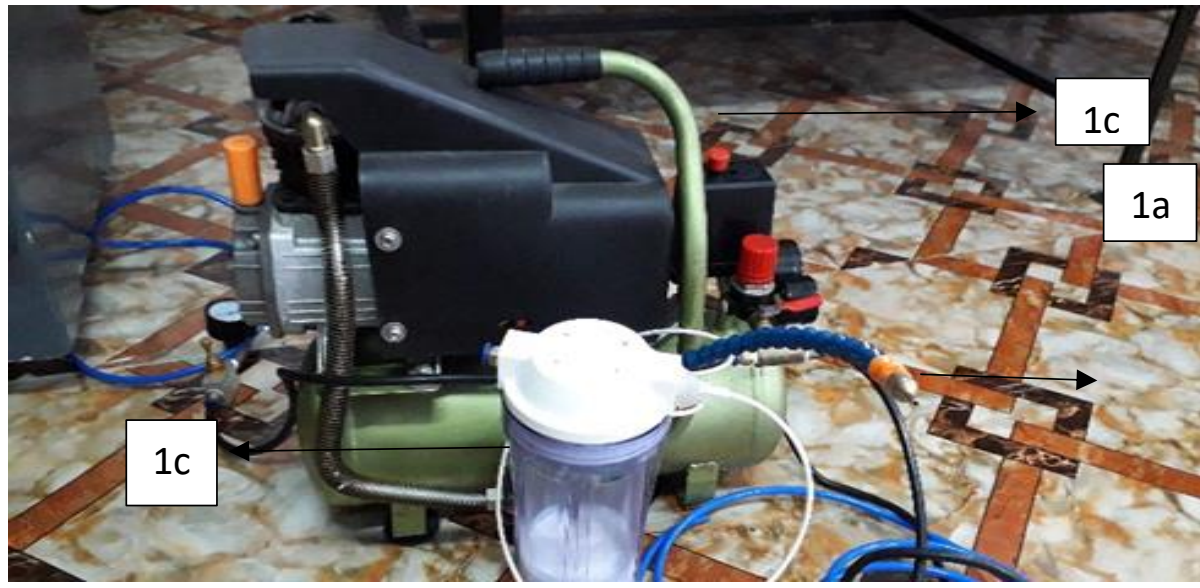

Figure 1: High speed cutting fluid with compressor: (1a) Nozzle (1b) Compressor (1c) cutting fluid reservoir 


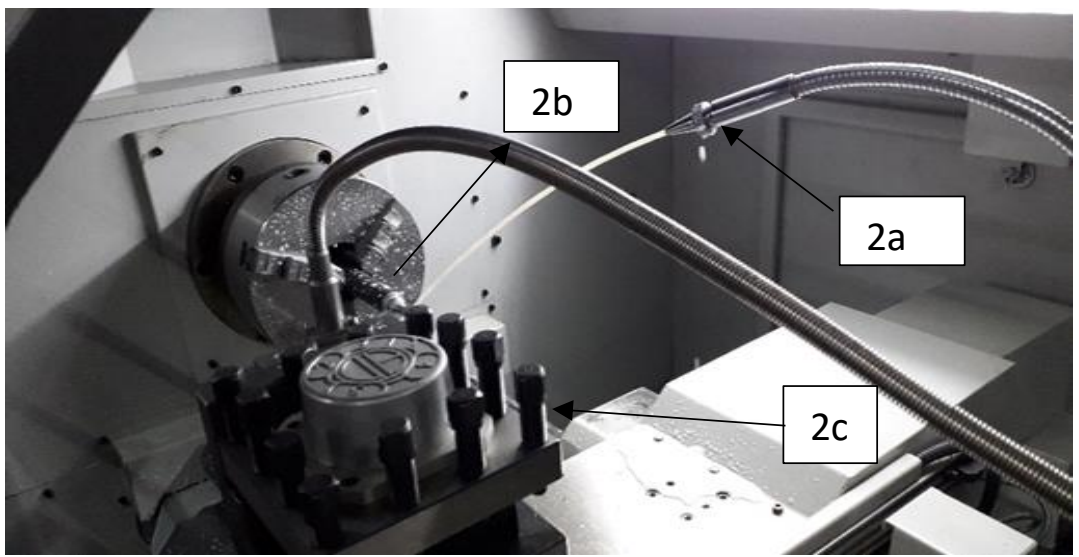

Figure 2: Conventional cutting set up: (2a) Nozzle (2b) Work piece material (2c) Tool post

In figure 1 represents the set up for high speed cutting fluid with compressor where lubricant (grade 60) and air is mixed by MQL set up based on spray gun of CNC lathe (Model: CK6136A-2, made in China). The two separate hollow pipes carry lubricant and air which mixed in mixing chamber (white colour) and just before the tip of the nozzle. The lubricant flow is controlled by flow control valve. In order to have contentious mist, constant pressure is assured by the pressure gauge reading because change in pressure may vary quantity of the lubricant coming out of the nozzle and outer diameter of nozzle is $2.5 \mathrm{~mm}$. Experiments are carried with the following parameter viz. Coolant pressure, spot distance, coolant flow rate are 5 bar, $20 \mathrm{~mm}, 850 \mathrm{ml} / \mathrm{hr}$. From Figure 2 it is shown that the photographic view of conventional cutting fluid on machining process. In Figure 3, it has shown that the schematic view of MQL set up and all accessories which are to be needed for this system.

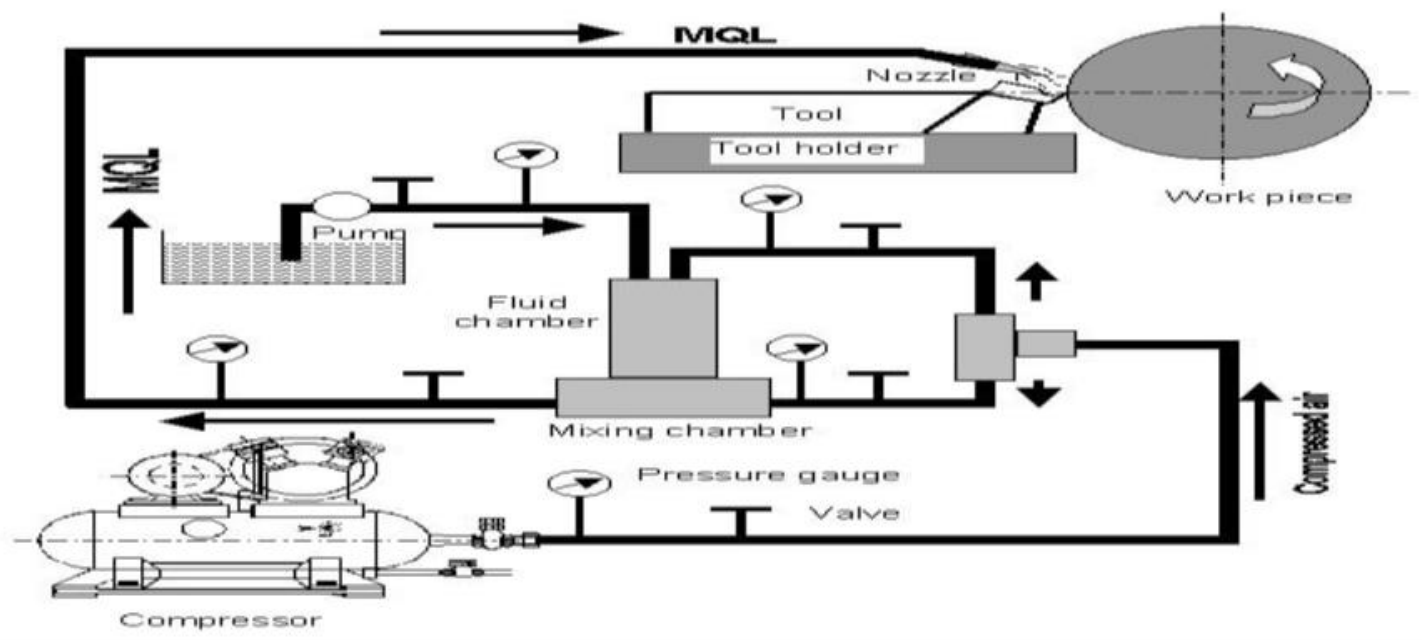

Figure 3: Schematic view of MQL set up

The schematic view of minimum quantity lubrication system set up shows by figure 3 [1]. The conventional cutting fluids are not effective in such high production machining, particularly in continuous cutting of materials like steel and alloy. Minimum quantity lubrication presents itself as a viable alternative for turning with respect to tool wear, heat dissipation, and machined surface quality.

\section{EXPERIMENTAL METHOD AND SAMPLE PREPARATION}

The experimental set-up consists of a CNC lathe (Model: CK6136A-2) machine. The experiment done using two types of cutting fluids. One is conventional cutting fluid and another is minimum quantity lubrication which is extremely small amount of cutting fluids. The requirements of Minimum Quantity Lubrication is supplied by the MQL system during the experiment at 5 bars pressure. The MQL system is a superfine particle oil mist generator capable of supplying superfine particles of oil-air mixture from an ejecting nozzle, while discharging cutting oil at a level of 850$1000 \mathrm{ml} / \mathrm{hr}$. The work piece $(\varnothing 81 \mathrm{~mm} \times \mathrm{L} 457.2 \mathrm{~mm})$ material is shown in Figure 4 is a cylindrical round bar of Mild Steel and consists of hardness is (48-50) HRC. A tungsten carbide tool is shown Figure 5 which is used for this experiment which contain $(\mathrm{L}=8.7 \mathrm{~mm}, \mathrm{I} . \mathrm{C}=12.7 \mathrm{~mm}, \mathrm{r}=0.8 \mathrm{~mm}, \mathrm{~d}=5.16 \mathrm{~mm})$ specification with WNMG tool holder. The MQL system generates the oil mist based on the principle of Minimum Quantity Lubrication, oil mist generator. The experiment is carried out at three cutting speeds are 600,700 and $800 \mathrm{rev} / \mathrm{min}$ at 60,70 and 80 $\mathrm{mm} / \mathrm{min}$ feed rate with 015,020 and $0.30 \mathrm{~mm}$ depth of cut. 


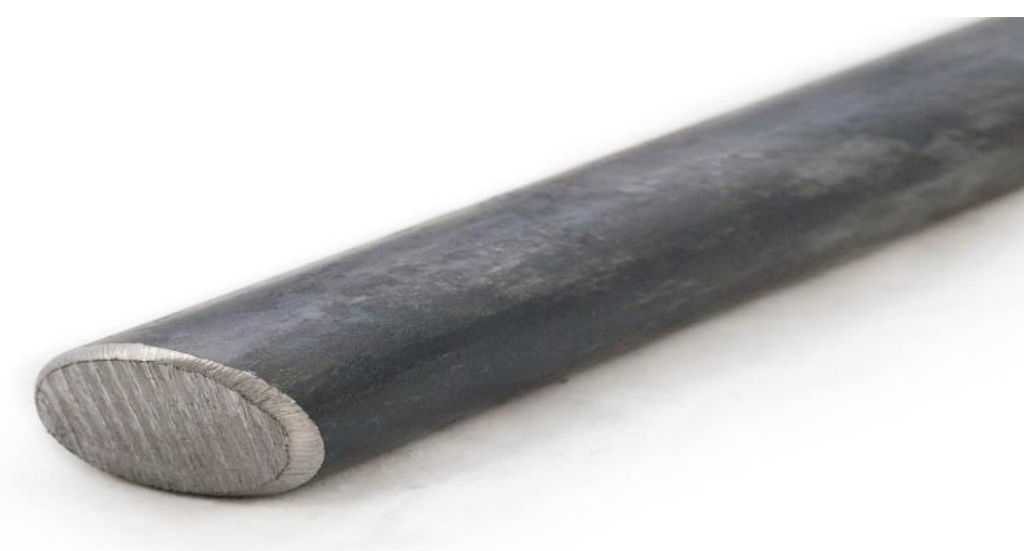

Figure 4: Work piece raw material (Mild steel 50HRC)

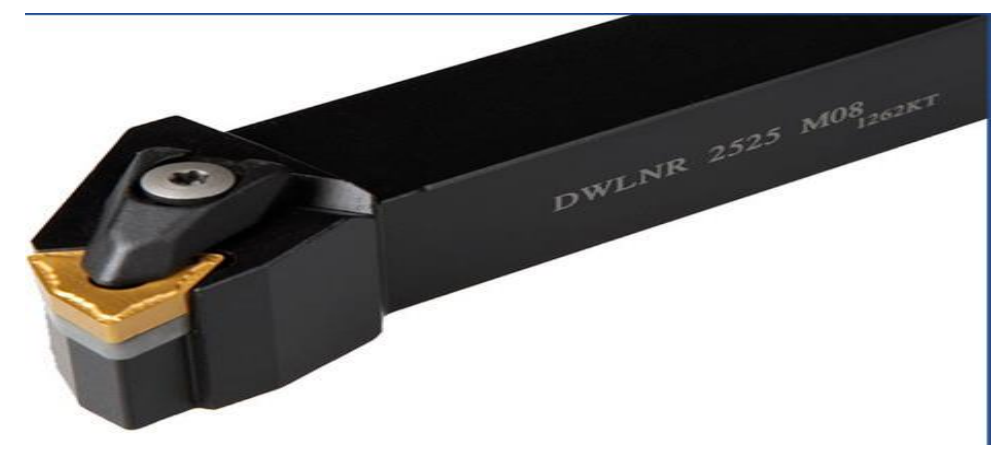

Figure 5: WNMG tool holder with insert

Table 1: Experimental Data

\begin{tabular}{|c|c|c|c|c|c|c|}
\hline \multirow[t]{2}{*}{ SL. No. } & \multirow[t]{2}{*}{$\begin{array}{l}\text { Cutting speed } \\
\text { (rev/min) }\end{array}$} & \multirow[t]{2}{*}{$\begin{array}{l}\text { Feed rate } \\
(\mathrm{mm} / \mathrm{min})\end{array}$} & \multirow[t]{2}{*}{$\begin{array}{l}\text { Depth of cut } \\
(\mathrm{mm})\end{array}$} & \multicolumn{3}{|c|}{$\begin{array}{l}\text { Response parameters } \\
\text { Surface roughness }(\mu \mathrm{m})\end{array}$} \\
\hline & & & & Dry & Flooded & MQL \\
\hline 1 & 600 & 60 & 0.15 & 2.31 & 2.25 & 1.85 \\
\hline 2 & 600 & 60 & 0.20 & 2.12 & 2.38 & 1.67 \\
\hline 3 & 600 & 60 & 0.25 & 2.40 & 2.11 & 1.56 \\
\hline 4 & 600 & 60 & 0.15 & 1.95 & 1.89 & 1.48 \\
\hline 5 & 600 & 60 & 0.20 & 2.10 & 1.97 & 1.69 \\
\hline 6 & 600 & 60 & 0.25 & 1.96 & 1.84 & 1.35 \\
\hline 7 & 600 & 60 & 0.15 & 1.88 & 1.76 & 1.23 \\
\hline 8 & 600 & 60 & 0.20 & 2.22 & 1.72 & 0.98 \\
\hline 9 & 600 & 60 & 0.25 & 1.91 & 1.68 & 0.90 \\
\hline 10 & 600 & 60 & 0.15 & 1.75 & 1.66 & 1.20 \\
\hline 11 & 600 & 60 & 0.20 & 2.40 & 1.78 & 1.11 \\
\hline 12 & 600 & 60 & 0.25 & 2.10 & 1.63 & 0.87 \\
\hline 13 & 600 & 60 & 0.15 & 1.89 & 1.53 & 0.79 \\
\hline 14 & 600 & 60 & 0.20 & 1.77 & 1.66 & 0.84 \\
\hline 15 & 600 & 60 & 0.25 & 1.82 & 1.75 & 0.68 \\
\hline 16 & 600 & 60 & 0.15 & 1.93 & 1.52 & 0.72 \\
\hline 17 & 600 & 60 & 0.20 & 1.78 & 1.60 & 0.80 \\
\hline 18 & 600 & 60 & 0.25 & 2.12 & 1.58 & 0.78 \\
\hline
\end{tabular}




\section{RESULT AND DISCUSSION}

The experiments were designed by using various methods with Minitab 19 software. The surface roughness are determined by three cutting condition such as dry, conventional flood and MQL systems. From these, the best and optimal results are found by using Minitab software. At first specimen is prepared and experiments are carried out in CNC Lathe machine. To visualize the effect of cutting speed (Cs) depth of cut (DOC) over surface roughness parameters (Ra) of dry, flooded and MQL condition are shown in following Figures 6-8.

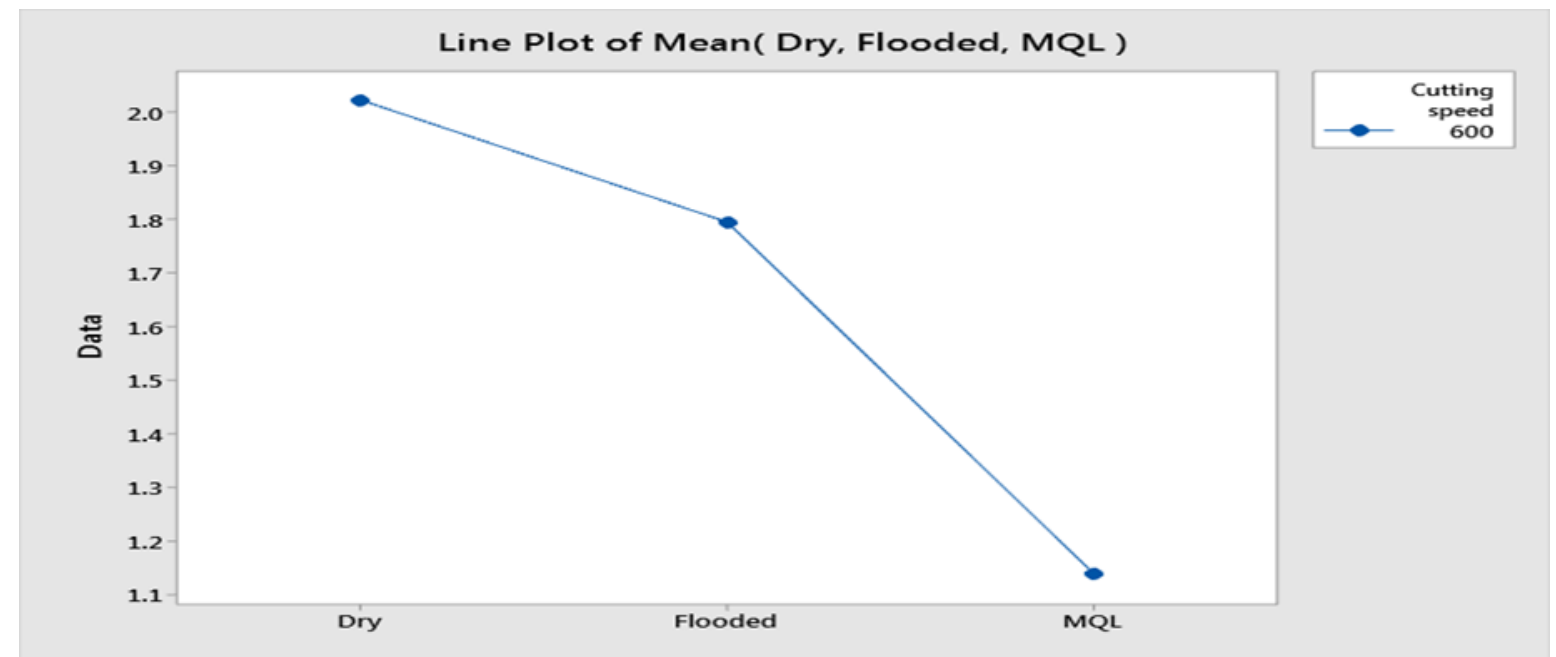

Figure 6: Analysis of line plot of mean surface roughness for cutting speed (Cs).

The concept of minimum quantity lubrication (MQL) has been suggested since a decade ago as a means of addressing the issues of environmental intrusiveness and occupational hazards associated with the airborne cutting fluid particles on factory shop floors. In figure 6 represents the analysis of line plot of mean surface roughness for cutting speed (Cs) of $600 \mathrm{rpm}$. As shown in Figure 6, the mean is the average of the number (response data) and it is used to analyse the way in which the mean varies across different groups of data. As the experiment are done with constant cutting speed, constant feed rate with varies of depth of cut, so it is drawn two line plot figure for dry, flooded and MQL over two cutting condition. In the Figure 6 , it is clear that when cutting speed is constant and applying MQL system the surface roughness value is significant over dry and flooded condition.

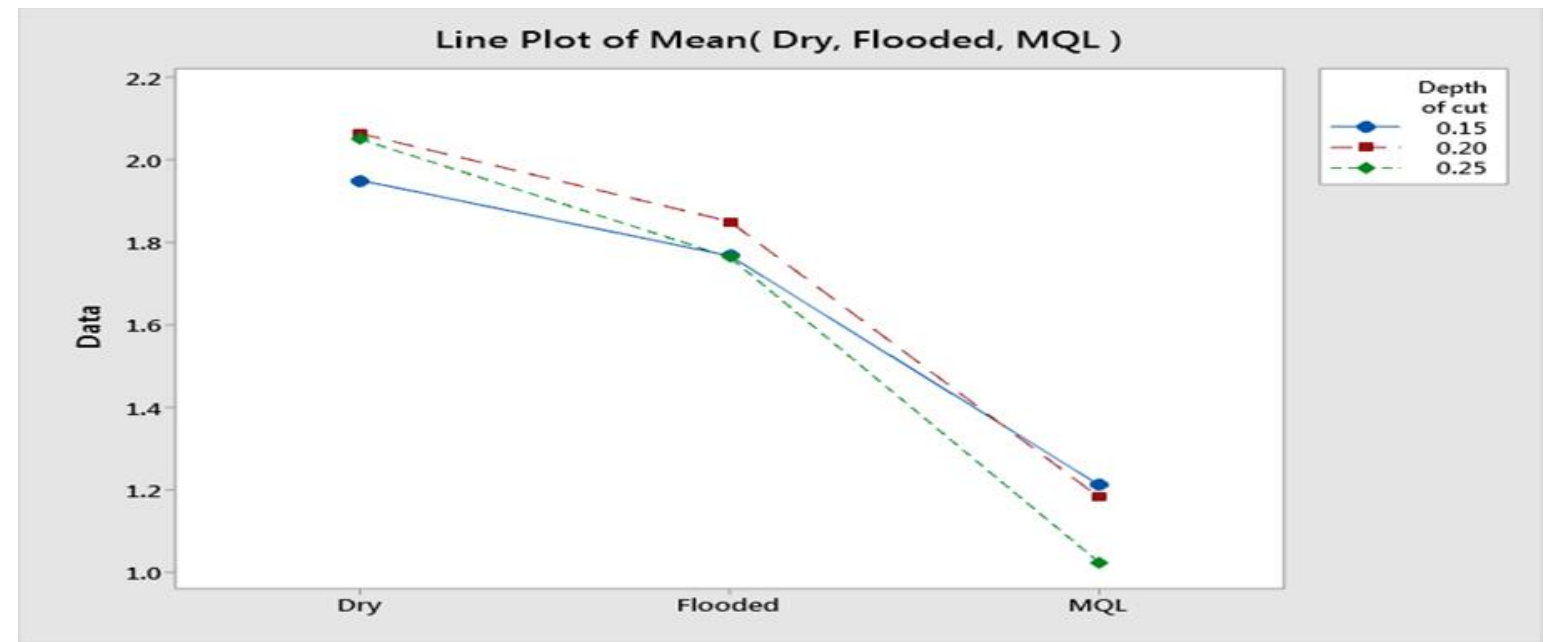

Figure 7: Analysis of line plot of mean over depth of cut (DOC)

Figure 7 shows the analysis of line plot of mean over depth of cut (DOC). As can be seen in the Figure 7, with small change of depth of cut, the surface roughness in the machining becomes optimum for MQL system comparing with those for dry and flooded situation. When depth of cut is $0.25 \mathrm{~mm}$ (green colour), MQL system show the excellent result of surface roughness than others two depth of cut. In conclusion, it can be said that the cutting performance of MQL system of machining is better than that of dry and conventional machining. As per as MQL is concerned surface roughness value is almost constant with little variations. Minimum quantity lubrication (MQL) and cryogenic cooling system has been developed now a days for better surface roughness, temperature and tool life. Also, MQL reduced 
average auxiliary flank wear and notch wear on auxiliary cutting edge, surface roughness also grew very slowly under MQL condition.

Surface roughness is also an important index of machinability or grind ability because performance and service life of the machined component are often affected by its surface finish. MQL cooling effect also improved to some extent with the decrease in feed particularly at lower cutting velocity.

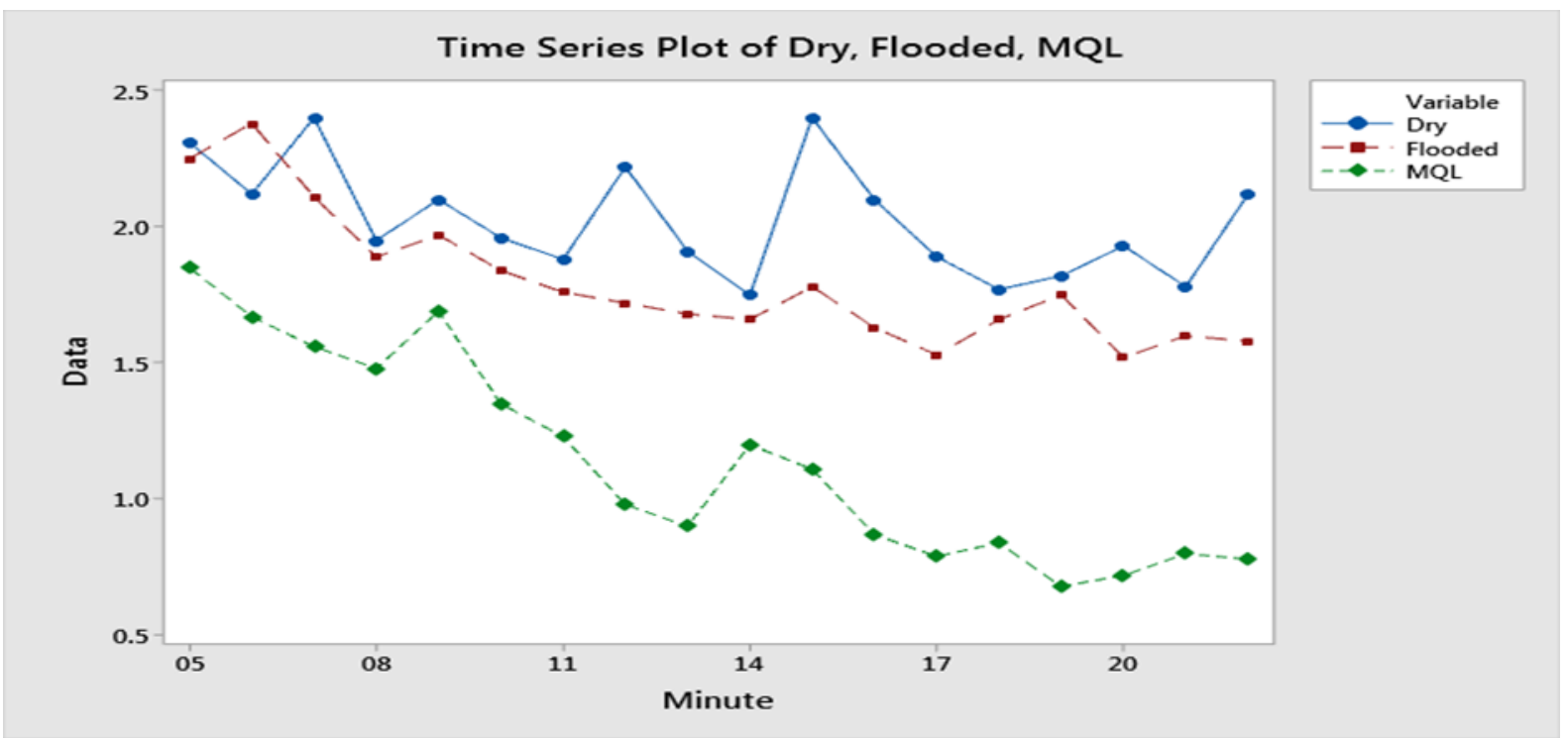

Figure 8: Time series plot of surface roughness for dry, flooded and MQL

In figure 8 shows the time series plot of surface roughness for dry, flooded and MQL. As can be seen in the Figure 8, it is clearly shows that the surface roughness value is optimal than dry and flooded condition. With increasing machining time MQL show better surface roughness with gradually. The machining temperature at the cutting zone is an important index of machinability and needs to be controlled as far as possible. MQL is expected to provide some favourable effects mainly through reduction in cutting temperature. With the increases of machining time the surface roughness value of MQL machining is excellent than dry and flooded machining.

\section{CONCLUSION}

In the cutting performance of machining, MQL provides the better surface roughness result than dry and flooded condition which are shown from the experiment. Not only surface roughness, but MQL also provided reducing tool wear, improved tool life and better surface finish as compared to dry and flooded machining of steel. In this study, MQL provides several benefits in the machining of $50 \mathrm{HRC}$ steel. The main objective of the present work was to experimentally investigate the role of minimum quantity lubrication (MQL) on surface roughness in turning operation $50 \mathrm{HRC}$ steel and compared the effectiveness of MQL with that of dry and conventional flood. The findings of the present experimental investigation can be written in the following way.

1. MQL machining of surface roughness is seen to be significant and optimal when compared with the dry and flooded.

2. It is evident that MQL improves surface roughness finish depending upon the work-tool materials and mainly through controlling the deterioration of the auxiliary cutting edge.

3. It is appeared that MQL system grows quite fast under dry and conventional machining due to more intensive temperature.

\section{FUTURE SCOPES OF MQL}

The future direction of MQL can be illustrated in the following way.

- Metal cutting is one of the most extensively used manufacturing processes, and its technology continues to advance in parallel with the developments in material from surface of a work-piece to achieve the desired product and researcher always tried to fulfilled the requirement.

- The new method of minimum quantity lubrication (MQL) system is the delivering metal cutting fluid to the chip-tool interface and by this method, a little fluid, when properly selected and applied, can make a substantial difference in how effectively a tool performs and is to reduce the machining costs by improving its quality and productivity.

- $\quad$ MQL is a most environment friendly method and used to minimize the negative aspects of cutting fluid which will be most helpful for researcher in their further research work. 
- $\quad$ IV. By using MQL system it is possible to reduce friction, cooling and flushing away chips. The cutting performance of MQL machining is better than that of conventional machining. Researchers will be more benefits for future research work in this field.

- MQL provides the benefits mainly by reducing the cutting temperature, which improves cooling effect and results in better surface finish.

\section{ACKNOWLEDGEMENTS}

The authors would like to acknowledge the Teachers and staffs in the Industrial and Production Engineering Department, DUET, Gazipur, Bangladesh for the entire supports and valuable suggestions and helps during the entire experimental work.

\section{REFERENCES}

[1] Dhar N R, Islam S, Kamruzzaman M, (2007) Effect of minimum quantity lubrication (MQL) on tool wear, surface roughness and dimensional deviation in turning AISI-4340 steel G.U. J. Science 20(2): 23-32.

[2] Liao Y S, Lin H M (2007) Mechanism of minimum quantity lubrication in high-speed milling of hardened steel. International Journal of Machine Tools \& Manufacture 47(11):1660-1666

[3] Lugscheider E, Knotek O, Barimani C, Leyendecker T, Lemmer O, and Wenke R, (1997) Investigation on hard coated reamers in different lubricant free cutting operations, Surface and coating Technology, 90: 172-177

[4] Dhar N R, Islam M W, and Mithu M A H,(2006) the influence of minimum quantity of lubrication on cutting temperature, chip and dimensional accuracy in turning AISI-1040 steel, Journal of material processing technology, 171: 93-99.

[5] Derflinger V, Brandle $\mathrm{H}$, and immermann $\mathrm{H}$, (1996) new hard/ lubricant coating for dry machining, Surface coating technology, 113: 286-292.

[6] Brager D U, Dini A E, Mirranda and Coppini N L, (1999) Minimal lubricant in the drilling process of aluminium-silicon alloy-A356 (SAE 323), Proc. Of the $3^{\text {rd }}$ int. Machining am grinding conf. (SME), Cincinnmi, USA, 1: 683-697.

[7] Rahman K M, (2004) Effect of minimum quantity lubrication in drilling commercially used steels, M. Engg. Dissertation, BUET, Dhaka, Bangladesh.

[8] Khan M M A, M A H Mithu, Dhar N R, (2009) Effects of minimum quantity lubrication on turning AISI 9310 alloy steel using vegetable oil-based cutting fluid. Journal of materials processing technology, 209, 15-16: 5573-5583.

[9] Dhar N R, Ahmed M T, Islam S, (2007) An experimental investigation on effect of minimum quantity lubrication in machining AISI 1040 steel. International journal of machine tools and manufacture. 475: 748-753.

[10] Dhar N R, Siddiqui A T and Rashid M H, (2006), Effect of High Pressure Coolant Jet on Grinding Temperature, Chip and Surface Roughness in Grinding AISI-1040 Steel, ARPN Journal of Engineering and Applied Sciences. Vol. 1(4): pp. 22-28.

[11] Huang, Y. and Liang, S.Y., 2003, "Modelling of the Cutting Temperature Distribution under the Tool Flank Wear Effect”, Journal of mechanical engineering science, Vol. 217(11), pp. 1195-1208.

[12] Benardos P G, Vosniakos C C (2003) Predicting Surface roughness in Machining: a review. Int. Mach. Tools Manuf. 43:833-844.

[13] Lohar D V and Nanavaty C R, (2013) Performance Evaluation of Minimum Quantity Lubrication (MQL) using CBN Tool during Hard Turning of AISI 4340 and its Comparison with Dry and Wet Turning. Bonfring International Journal of Industrial Engineering and Management Science 3-3: 102106.

[14] Kedare S B, Borse D R, and Shahane P T (2014) Effect of Minimum Quantity Lubrication (MQL) on Surface Roughness of Mild Steel of 15HRC on Universal Milling Machine. 3rd International Conference on Materials Processing and Characterization. Vol 6: 150-153.

[15] Liao Y S, Lin HM (2007) Mechanism of minimum quantity lubrication in high speed milling of hardened steel. International journal of machine tools and manufacture. 47 (2007), pp: 1660-1666.

[16] Zhou J M, Bushlya V, and Stahl J E (2012). An investigation of surface damage in the high speed turning of Inconel 718 with use of whisker reinforced ceramic tools. Journal of Materials Processing Technology 212: 372- 384.

[17] Çakır O, Kıyak M, and Altan E, (2004) Comparison of gases applications to wet and dry cuttings in turning. International Journal of Materials Processing Technology. 153-154: 35-41.

[18] Chorng-Jyh T, Yu-Hsin Linb, Yung-Kuang Yanga, Ming-Chang Jengc (2009) Optimization of turning operations with multiple performance characteristics using the Taguchi method and Grey relational analysis." journal of materials processing technology. Vol-209: 2753-2759. 
[19] Varadarajan A S, Philip P K, and Ramamurthy B, (2002) Investigations on hard turning with minimal cutting fluid application (HTMF) \& its comparison with dry \& wet turning. International Journal of Machine Tools \& Manufacture 42: 193-200.

[20] Feng CX J, Wang X, (2002) Development of empirical models for surface roughness prediction in finish turning.Int. J. Adv. Manuf. Technol.20: 348-356.

[21] Karayel D (2009) Prediction and Control of surface roughness in CNC Lathe using artificial neural network, Journal of Material Processing Technology. 209: 3125-3137.

[22] Tsai M.K., Lee B.Y., Yu S.F., 2007. A predicted modeling of tool life of high-speed milling for SKD61 tool steel. Int J Adv Manufacturing Technology.26: 711-717.

[23] Karayel D (2009) Prediction and Control of surface roughness in CNC Lathe using artificial neural network, Journal of Material Processing Technology. 209: 3125-3137.

[24] Brain Boswell, Mohammad Nazrul Islam (2012), feasibility study of adopting minimum quantities of lubrication for end milling aluminum processing's of the World Congress on Engineering Vol. 3.

[25] Cha, Jinhoon, \& Han, Sangbo. (2010). Searching optimal cutting condition for surface roughness in turning operation on Inconel 718 using Taguchi method. Journal of the Korean society of machine tool engineers, 19(2): 295-300.

[26] Lee, J.H, Ko, T.J,. \& Baek, D.G. (2009). A study on optimal cutting condition of MQL milling using response surface analysis. Journal of the Korean society of machine tool engineers, 26(1): 43-50.

[27] Amla Patil, Jay Raval, Tim Bangma, Immanuel Edinbarough, Bruce Tai, David Stephenson, Suleiman Obeidat and Wayne Nguyen Hung (2020). International Journal of Engineering Materials and Manufacture (2020) 5(4) 98-115. 